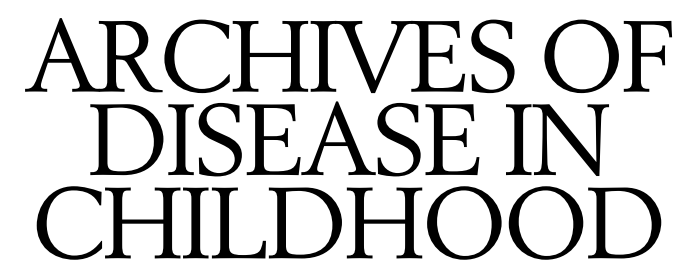

The Fournal of the Royal College of Paediatrics and Child Health

\title{
Annotations
}

\section{Short QTc interval as an important factor in sudden infant death syndrome}

In 1997, 403 babies in England and Wales died suddenly, unexpectedly, and for no reason (despite a thorough postmortem examination) - a rate of 0.63 per 1000 live births (press release from the Foundation for the Study of Sudden Infant Death, August 1998). It is salutary to recall that 10 years ago the rate of sudden infant death syndrome (SIDS) was 2.3 per 1000 live births. ${ }^{1}$ Much of this remarkable improvement, a trend shared by many other Western countries, is attributed to the simple four point advice included in the "reduce the risk" campaign first launched in Britain in November 1991, in particular, the importance of avoiding the prone sleeping posture (although it is worthy of note that the incidence of SIDS had begun to fall a few years before this). This success story should however, not be allowed to conceal the continuing tragedy of about nine babies each day who are victims of SIDS. This residuum (still constituting the largest single group of deaths in infants 1 week to 1 year old) is stubbornly resisting attempts to shift it - the incidence of SIDS has not changed significantly since 1995 .

Most of these deaths are in families where mothers smoke during pregnancy and where there is household exposure to tobacco smoke after birth. ${ }^{2}$ Some view this association a direct one ${ }^{2}{ }^{3}$ : exposure to products of cigarette smoke before and after birth perhaps interfering with lung growth or neural mechanisms involved in the control of breathing. Stopping parents smoking, it has been estimated, could reduce the risk of SIDS by almost two thirds. ${ }^{2}$ But it is also important to consider the additional possibility that smoking is a marker for other, as yet unknown, pathophysiological mechanisms leading to death, with which adverse social circumstances (particularly the illegal use of drugs, less awareness of risk factors, poverty, poor education, inadequate parenting, history of child abuse or neglect) are especially associated. ${ }^{24}$

\section{Multifactorial pathophysiology: the "jigsaw" hypothesis}

We also have to recognise that it is still not known, in spite of much research and speculation, how sleeping posture influences risk; indeed, one study from Victoria, Australia, examining ethnic variation and risk of SIDS, did not show sleeping position or cigarette smoking as having any influence on the risk of death. ${ }^{5}$ We remain ignorant of the pathophysiology of SIDS, although a defect in the neural control of breathing is viewed as an important possible mechanism. There is no reason that the cause of SIDS should not be multifactorial. I believe all infants are poten- tially vulnerable to sudden unexpected death, risk factors for this being as pieces of a jigsaw; only when the puzzle is complete will the baby die. According to this hypothesis, each baby has a different and unique jigsaw of risk factors and what we are doing by reducing the risk is to manipulate the pieces we know for the whole infant population, an approach that has met with remarkable success. Or, as Bergman has so eloquently put it: "SIDS is like a nuclear explosion where the critical mass must be obtained before the event is to occur." Avoidance of risk factors prevents this critical mass being attained. To reduce the risk further, to try to shift the stubborn residuum of deaths, we need to identify other risk factors and, if possible, mechanisms of their action.

\section{Prolongation of QT interval}

It is against this background that the recently reported prospective study, by Schwartz et al from the University of Pavia, Italy, of the clinical association between prolongation of the QT interval in electrocardiographs (ECGs) of neonates and risk of later SIDS, is of particular interest. ${ }^{7}$ In this remarkable study, 33034 ECGs taken on the 3rd or 4th day after birth from healthy babies born in 1976-94 were analysed to measure QT interval corrected for heart rate (QTc) and the babies followed for one year. During this period there were 34 deaths, 24 attributed to SIDS, an incidence of 0.7 per 1000 live births. Twelve of the 24 SIDS victims had a longer QTc interval (mean (SD) 435 (45) $\mathrm{ms}$ ) than infants who were alive at 1 year (400 (20) $\mathrm{ms}$ ) or who died from other causes (393 (24) ms). Half of the infants who died of SIDS had a prolonged QTc compared with none of the survivors or infants who died from other causes. The odds ratio for SIDS in infants with a prolonged QTc (>440 ms) was about 41 , significantly higher than the odds ratio for traditional factors such as prone posture and maternal smoking.

The QTc interval is a marker for ventricular repolarisation; prolongation of this interval, a developmental abnormality in cardiac sympathetic innervation, points to reduced cardiac stability favouring susceptibility to potentially lethal ventricular fibrillation. It is associated with death in some clinical conditions ${ }^{8}$ and in apparently healthy people. ${ }^{9}$ This is not the first time a cardiac arrhythmia has been postulated to explain $\operatorname{SIDS}^{10}$ but, until now, substantial evidence has not been forthcoming. The QTc increases during the 2 nd month of life, peaks between the 2nd and 3rd, and declines to birth values by about 6 months. ${ }^{11}$ Thus a tendency towards reduced cardiac stabil- 
ity closely parallels the known epidemiology of SIDS. Available evidence suggests that $30 \%$ to $35 \%$ of infants later to become victims of SIDS can be expected to have a prolonged QTc interval in the first week.

What are the implications of these findings for paediatric practice, especially for the prevention of SIDS? There can surely be no justification to consider all newborn babies for routine ECGs on the 3rd or 4th day of life. The main drug treatment for prolonged QTc interval is $\beta$ blockers and Schwartz et al postulate that 100 infants would need to be treated to save the lives of two babies. ${ }^{7}$ Even if this were to be remotely successful, considering iatrogenic harm to the remaining 98 significantly weakens the case, let alone the enormous worry to families in revealing this diagnosis. But in babies with a family history of SIDS, prolonged QTc or other unexplained life threatening events, selective ECGs on days $3-4$ of life could be taken with a view to treating those babies discovered to have a prolonged QTc for as long as it takes the QTc to return to normal. We will have to be guided by our cardiology colleagues for some of the answers to these difficult issues if effective preventive intervention is ever to be targeted for those particularly at risk.

\section{QTc interval and stress}

Let us make a lateral move and return to the increased risk of SIDS in families who live in a parlous state of serious social disadvantage containing the various elements of social adversity and personal stress I have previously alluded to. If we recognise that there will be babies born to these families who have a prolonged QTc, could it be that this vulnerability, under certain circumstances, might lead to a life threatening arrhythmia? Lethal arrhythmias associated with prolonged QTc interval are usually triggered by sudden increase in sympathetic activity. ${ }^{12}$ Does stress in a baby cause increased catecholamine release? We know infants undergoing heel stab blood tests cry, show facial grimacing, have an increase in baseline heart rate, and increased variability of heart and respiratory rate, ${ }^{13}{ }^{14}$ features strongly suggesting increased catecholamine release associated with pain. Preterm infants receiving intensive care have been shown to have lower adrenaline concentrations when sedated with morphine. ${ }^{15}$ Studies in infant and adult rodents have apparently shown that the "innate fear paralysis reflex" produced by a range of frightening stimuli of the type that commonly occur in daily life transiently prolongs the QT interval and is associated with bradycardia and changes in the $\mathrm{T}$ wave. ${ }^{16}$ Visiting the homes of many SIDS victims often shows a picture of chaos, a smokey atmosphere, very poor housing, obvious social stresses, and a pre-existence of child abuse or drug abuse in the family (Davis $\mathrm{P}$, personal communication, 1998). Expressions of this social dysfunction include irregular feeding, being left alone for long periods of time, infrequent changes of nappies, exposure to cold, poor hygiene, and haphazard sleeping routines. It is likely, therefore, that this type of home environment is a source of potential serious stress for the baby. Could it be that this stress is, on occasion, another piece of the jigsaw causing increased catecholamine release that increases the risks of cardiac arrhythmias where there is a prolonged QTc interval? We need to research how severe social adversity and its parenting consequences might stress the baby, along with its pathophysiological consequences. How encouraging, therefore, to discover that one of the new directions of research into SIDS, currently supported by the Foundation for the Study of Sudden Infant Death, is to look into wider issues of general infant care-especially in low income families at relatively high risk of SIDS. ${ }^{17}$ Ignorance of the influences of parenting on babies' physiology should not prevent us from continuing to emphasise to parents the common sense of good, responsible, infant care. Babies must be fed regularly, changed frequently, sleep routines encouraged, not left alone for long periods, physical and emotional contact nurtured, as well as obvious issues of laying babies on their backs and avoiding smoking. They must be cherished, looked after with great care, and considered extremely vulnerable - a concept highlighted by Gantley et al in their anthropological study of Bangladesh parents and infant caregiving practices in Cardiff, a population at particularly low risk for SIDS. ${ }^{18} \mathrm{~A}$ mismatch in a baby of a prolonged QTc with stress factors could increase Bergman's critical mass, with its tragic outcome.

Is this stretching speculation too far? I believe no more so than many other hypotheses that have been proposed to explain sudden and unexplained infant death. No more than the empirical observations many years ago that simply putting babies to lie on their backs from the prone posture would significantly reduce risk. In 1984, in a study highlighting the rarity of SIDS in Hong Kong, I reflected that "influences of lifestyle and caretaking practices on risks of cot death were being underestimated in preference for more exotic and esoteric explanations". ${ }^{19}$ I am still of this opinion and hope Schwartz et al's studies will indirectly continue the momentum of researching the home environment in which young babies are nurtured at such a critical stage of their development. One consequence of this might be a continuing reduction in the risk of SIDS.

D P DAVIES

Department of Child Health,

University of Wales College of Medicine,

Heath Park, Cardiff CF4 $4 X N$, UK

1 Monitor: Population and Health. London: Office for National Statistics. DH3 98/2, 1997.

2 Blair PS, Fleming PJ, Bensley D, et al. Smoking and the sudden infant death syndrome: results from 1993-95 case control study for confidential inquiry into stillbirths and deaths in infancy. BMF 1996;313:195-8.

3 Mitchell EA, Ford RPK, Stewart AW, et al. Smoking and the sudden infant death syndrome. Pediatrics 1993;91:893-6.

4 Davis P, Davies DR. Sudden, unexplained infant deaths in South Glamorgan 1993-96: a worrying social residuum. Welsh Paediatric fournal 1997;9:48-51

5 Potter A, Lumley J, Watson L. The "new" risk factors for SIDS: is there an association with the ethnic and place of birth differences in incidence in Victoria, Australia. Early Hum Dev 1996;45:119-21.

6 Bergman A. The discovery of sudden infant death syndrome: lessons in the practice of political medicine. New York: Praeger, 1996:17.

7 Schwartz PJ, Stramba-Badiale M, Segantini A, et al. Prolongation of the OT interval and the sudden infant death syndrome. N Engl $f$ Med 1998;383:1709-14

8 Schwartz PJ, Locati E, Napolitana C, Prior SG. The long QT syndrome. In: Zipes DP, Jalife J, eds. Cardiac electrophysiology: from cell to bedside. 2nd ed. Philadelphia: WB Saunders 1995:788-811.

9 Schouten EG, Dekker JM, Meppelink P, et al. QT interval prolongation predicts cardiovascular mortality in an apparently healthy population. Circulation 1991;814:1516-23.

10 Schwartz PJ. Cardiac sympathetic innervation and the sudden infant death syndrome: a possible pathogenic link. Am f Med 1976;60:167-72.

11 Schwartz PJ, Montemerlo M, Facchini M, et al. The QT interval throughout the first six months of life: a prospective study. Circulation 1982;66:496501

12 Schwartz PJ, Prior SG. Sympathetic nervous system and cardiac arrhythmias. In: Zipes DP, Jalife J, eds. Cardiac electrophysiology: from cell to bedside. Philadelphia: WB Saunders, 1990:330-43.

13 Owens ME, Todt EH. Pain in infancy: neonatal reaction to heel lance. Pain 1984;20:77-86.

14 Grunah RVE, Craig KD. Pain expression in neonates: facial action and cry. Pain 1987;28:395-410.

15 Quinn MW, Wild J, Dean HG, et al. Randomized, double-blind controlled trial of the effect of morphine on catecholamine concentrations in ventilated preterm babies. Lancet 1993;342:324-7.

16 Kaada B. Sudden infant death-the QT interval in ECG and bradyarrythmias. Tidsskr Nor Laegeforen 1989;109:186-92.

17 News. Newsletter of the Foundation for the Study of Infant Deaths 1998;58:6.

18 Gantley M, Davies DP, Murcott A. Sudden infant death syndrome: links with infant care practices. BMF 1993;306:16-20.

19 Davies DP. Cot death in Hong Kong: a rare problem. Lancet 1984;ii: $1346-9$ 


\section{Post-traumatic stress disorder}

A 1996 report from the Child Accident Prevention Trust ${ }^{1}$ reminds us that "Every year in the UK about 700 children die, 120000 are admitted to hospital, and over 200000 attend accident \& emergency departments as a result of accidents." (The most common accidents were falls, followed by road traffic accidents.) Overall, $9 \%$ of the children attending three A\&E departments scored so highly on a screening scale for post-traumatic stress disorder (PTSD) that a diagnosis of PTSD was extremely likely. Half the children involved in road traffic accidents were judged likely to have PTSD. Other, larger studies of child survivors of road traffic accidents ${ }^{2}{ }^{3}$ found that $33 \%$ met criteria for a diagnosis of PTSD, with even more showing subthreshold clusters of distressing symptoms. After six months, one in six still presented with the full blown syndrome.

Until 15 years ago, it was widely accepted that most children responded to frightening events with transient distress and that not all children who experienced a potentially traumatic event reacted with disabling stress reactions. ${ }^{4}$ One reason for underestimating the effects of traumatic events on children was that the evidence was incomplete. Put simply, the bulk of the existing evidence came from data provided by parents and teachers. Few investigators had done what is now so obvious - they had not asked the children themselves!

PTSD was first officially recognised as a syndrome by the American Psychiatric Association in 1980. It was classified as an anxiety disorder and three main groups of symptoms were seen as characteristic: distressing and recurring recollections of the traumatic event; avoidance of stimuli associated with the trauma; and a range of signs of increased physiological arousal. ${ }^{5}$

Today, PTSD has become so widely discussed that trauma counsellors and specialists are expected to arrive in droves whenever major, and often minor, disasters occur. To some, it may seem that the disorder is potentially so commonplace as to have lost all credibility. ${ }^{6}$ I believe that PTSD is susceptible to clear diagnosis, that it is real, that it is distressing and disabling, that it can be long lasting, and that it can be treated. Moreover, paediatricians are very likely to encounter it among children who present following accidents, particularly road traffic accidents, and so they should consider ways to ameliorate the predictable emotional consequences of acts that bring children to $\mathrm{A} \& \mathrm{E}$ departments.

\section{Characteristics of PTSD}

When a child is faced with a very frightening, perhaps life threatening, situation he or she may become very distressed: crying, clinging, shaking with fear. If the upset is very great, they may go into shock and be largely unresponsive to outside stimulation for some time. These are normal reactions that have evolved as protective mechanisms. At times of danger, we need to be able to concentrate on what is threatening us to the exclusion of other, less relevant stimuli; we also need to be prepared to fight or flee. When the danger passes, a slow return to normal can usually be expected. But in some cases, such return to a normal state is elusive. Symptoms persist both day and night. This is when an adjustment reaction may develop into PTSD.

Following a traumatic event, children often need to be close to their parents for comfort and reassurance. This clinginess is understandable but may be extremely irritating to parents. Even teenagers may need to be reassured at night and often regress to sharing the parental bed. But the most troublesome symptom from the child's point of view can be the intrusive images of the event. These can occur at any time and are notable for their vividness. Usually the child "sees" the event replaying over and over again, but this can be accompanied by repetitive memories in any of the senses: sound, smell, touch, and motion. Occasionally, children will report that the experience is so vivid that they truly believe it is happening again. Such dissociative experiences are called flashbacks. Bad dreams and nightmares are also very common.

The intrusive images often come to the children as they are settling down for the night. They can be so distressing that children will fight against sleep and try to stay awake. It is ironic that children who are extremely tired try to stay awake with the obvious consequence that they become more tired, irritable, and unable to concentrate. The irritability can lead to anger that can be difficult to deal with. Children develop fears, especially of stimuli that were present when the traumatic event happened. For example, after the sinking of the cruise ship Fupiter, teenagers reported a profound increase in fear of drowning, fear of water in general, and fear of death and travel. ${ }^{7}$ Following road traffic accidents, children are likely to find it difficult to get back into cars for some time. Obviously, these fears have a survival value, but when extreme they can disrupt the child's and family's life.

In the immediate aftermath of an accident, children sometimes experience a great pressure to talk about what happened. Then, they often find it difficult to talk, especially with parents and friends. Anecdotally, many children report that they do not want to upset their parents when they talk about what happened and so they keep their feelings to themselves. In such circumstances, being able to talk to someone outside the family has obvious potential benefit.

Survivors have learned that life is very fragile. This can lead to a loss of faith in the future or a sense of foreshortened future. Their priorities change. Some feel they should live each day to the full and not plan far ahead. Others realise they have been over concerned with materialistic or petty matters and resolve to rethink their values. Their "assumptive world" has been challenged. ${ }^{8}$

Adolescent survivors report significantly high rates of depression, some becoming clinically depressed, having suicidal thoughts, and taking overdoses in the year after a disaster. A significant number become very anxious after accidents, although the appearance of panic attacks is sometimes considerably delayed. When children have been bereaved, they may need bereavement counselling.

Preschool children also develop distress that lasts beyond being an adjustment disorder and probably qualifies for the diagnosis of PTSD. In general, the DSM system is inadequate to reflect the stress reactions of very young children, ${ }^{9}{ }^{10}$ which include playing out the traumatic event repetitively, drawing it repetitively, and more unfocused aggression. ${ }^{11}$

\section{Precipitants of PTSD}

PTSD can follow any frightening event that is perceived by the child as being life threatening. Large scale disasters, such as shipping disasters, hurricanes, earthquakes, school shootings, and terrorist bombings ${ }^{12}$ seem so remote from everyday life that education, health, and social services took a long time to realise that children are more likely to 
be affected by a myriad of smaller, more personal disasters, which are nonetheless equally terrifying. Schools should prepare for children being maimed or killed while on the way to or from school. Children may get injured on school outings. Deranged individuals may enter school premises and hold children hostage or harm them. That is why schools have been urged to be "wise before the event"13 and prepare contingency plans to meet the emotional needs of children following such crises.

An important cause of PTSD in children is witnessing severe domestic violence, especially intrafamilial homicide. ${ }^{14}$ Civil conflict, urban violence, and war all affect large numbers of children, and one has to be aware that refugees from such conflicts may carry a heavy burden of traumatic stress.

\section{Persistence and high risk groups}

Nader et al reported a 14 month follow up of 100 children involved in a sniper attack on children at their school. ${ }^{15}$ The level of exposure to danger was strongly related to the severity of PTSD symptoms. In the most exposed groupthe children who had been directly in the line of fire-the scores on the measure of PTSD were very stable over the 14 month period.

In the seven year follow up of adolescent survivors of the Fupiter sinking, now in their early 20 s, preliminary findings indicate that overall $50 \%$ of the survivors had presented with PTSD at some point, mainly in the first few months. At follow up, around 15\% still met the criteria for PTSD with many more showing several signs of stress reaction that were not sufficient to meet diagnostic criteria. A high proportion were depressed and, although the numbers are small, the rate of suicide attempts was threefold that of a group of matched controls. ${ }^{16}$ Thus, PTSD must be considered as a seriously disabling disorder that can lead to interference in development and adjustment over many years.

In general, girls are more susceptible to PTSD than boys, and less able children are more badly affected than more able children. The objective severity of the trauma is directly proportional to the stress reactions, but subjective factors also mediate the effects. Both must be taken into account in formulating effective intervention. This means that when assessing a child, not only should one try to get a clear account of their perception of what occurred, one should also ask directly whether at any point they thought they were going to die. If people did die in the accident, or if people were badly injured, then the child is at greater risk of developing a stress reaction. Risk and protective factors are more fully discussed elsewhere. ${ }^{17}$

\section{Treatment}

Critical incident stress debriefing was originally developed to assist emergency personnel adjust to their emotional reactions to events encountered in the course of their rescue work. It makes use of group support techniques and has now been adapted for use with children following a wide variety of traumas. ${ }^{18}$ Following transport accidents, debriefing has been found to reduce levels of stress, particularly those manifested in intrusive thoughts. ${ }^{19-21}$ However, we still do not know when best to offer such debriefing to survivors of a disaster, nor indeed whether all survivors benefit.

\section{GROUP TREATMENT}

Where natural groupings exist in communities and schools, it makes sense to direct some support through such groups. ${ }^{19}{ }^{22-26}$ The aims of such groups should include the sharing of feelings, boosting children's sense of coping and mastery, and sharing ways of solving common problems. Different incidents may require different types of group intervention, for parents as well as children.

INDIVIDUAL TREATMENT

There is little evidence that drug treatment has a central role in PTSD, so the focus has been mainly on cognitive behavioural treatments that aim both to help the survivor make sense of what happened and to master their feelings of anxiety and helplessness.

Asking children to draw their experience often assists recall of both the event and the emotions ${ }^{22}{ }^{27}$ and are used as ways of assisting talking about the experience.

Most survivors recognise that sooner or later "they must face up to the traumatic event". The problem for the therapist is how to help the survivor re-experience the event and the emotions that it engenders in such a way that the distress can be mastered rather than magnified. Therapeutic exposure sessions that are too brief may sensitise rather than desensitise, ${ }^{28}$ so therapists may need to use much longer exposure sessions than normal. ${ }^{29}$ Recently, a procedure known as EMDR (eye movement desensitisation and reprocessing ${ }^{30}{ }^{31}$ ) has shown promise as a rapid treatment for some children. More comprehensive suggestions of useful techniques to promote emotional processing are given elsewhere ${ }^{28} 293233$

To date, there are insufficient controlled treatment interventions with individual cases, let alone randomised control trials; moreover, it is far from clear how best to involve families in treatment. There are clear pointers that parental reactions can help or hinder recovery, and treatment plans should take a family perspective even when the main thrust may be individual exposure work with the child.

\section{Implications for child health services}

Recent studies have clearly identified road traffic accidents and other childhood accidents as significant causes of serious and long lasting psychopathology in children and adolescents. ${ }^{34}$ While every effort must continue to reduce the number of road traffic accidents involving children, secondary prevention of the emotional consequences should be a priority in the already hard pressed $A \& E$ departments. Whatever the accident that leads a child to attend, part of the procedure should involve screening for emotional reactions and providing the child and parents with simple explanatory leaflets about possible emotional consequences and where to obtain further help locally should such reactions persist.

University of London, Institute of Psychiatry,

WILLIAM YULE

De Crespigny Park, London SE5, UK

1 Heptinstall E. Healing the hidden hurt: the emotional effects of children's accidents. London: Child Accident Prevention Trust, 1996.

2 DiGallo A, Barton J, Parry-Jones W, Road traffic accidents: early psychological consequences in children and adolescents. Br $\mathcal{F}$ Psychiatry psychological conseq

3 Mirza KAH, Bhadrinath BR, Goodyer I, Gilmour, C. Post-traumatic stress disorder in children and adolescents following road traffic accidents-a preliminary study. Br F Psychiatry 1998;172:443-7.

4 Garmezy N, Rutter M. Acute reactions to stress. In: Rutter M, Hersov L, eds. Child and adolescent psychiatry: modern approaches. 2nd ed. Oxford: Blackwell, 1985:152-76.

5 American Psychiatric Association. Diagnostic and statistical manual of mental disorders. 4th ed. Washington, DC: American Psychiatric Association, 1993.

6 O'Donohue W, Eliot A. The current status of post traumatic stress syndrome as a diagnostic category: problems and proposals. F Trauma Stress 1992;5:421-39.

7 Yule W, Udwin O, Murdoch K. The "Jupiter" sinking: effects on children's fears, depression and anxiety. F Child Psychol Psychiatry 1990;31:1051-61.

8 Janoff-Bulman R. The aftermath of victimization: rebuilding shattered assumptions. In: Figley CR, ed. Trauma and its wake. Vol 1. New York: assumptions. In: Figley CR,

9 Scheeringa MS, Zeanah CH, Drell MJ, Larrieu JA. Two approaches to the diagnosis of posttraumatic stress disorder in infancy and early childhood. $\mathcal{F}$ Am Acad Child Adolesc Psychiatry 1995;34:191-200. 
10 Almqvist K, Brandell-Forsberg M. Refugee children in Sweden: posttraumatic stress disorder in Iranian preschool children exposed to traumatic stress disorder in Iranian preschool ch
organized violence. Child Abuse Negl 1997;21;351-366.

11 Misch P, Phillips M, Evans P, Berelowitz M. Trauma in pre-school children: a clinical account. In: Forrest G, ed. Trauma and crisis management. London: Association for Child Psychology and Psychiatry, 1993:11-18.

12 Yule W. Posttraumatic stress disorder in children. Current Opinions in Pediatrics 1992;4:623-9.

13 Yule W, Gold A. Wise before the event: coping with crises in schools. London: Calouste Gulbenkian Foundation, 1993.

14 Harris Hendricks J, Black D, Kaplan T. When father kills mother: guiding children through trauma and grief. London: Routledge, 1993.

15 Nader K, Pynoos RS, Fairbanks L, Frederick C. Childhood PTSD reactions one year after a sniper attack. Am f Psychiatry 1991;147:1526-30.

16 Yule W, Bolton D, Udwin O, Boyle S, O'Ryan D, Nurrish J. The Jupiter sinking follow-up: 5-7 year outcome following a shipping disaster. European Association for Behavioural and Cognitive Therapy meeting, Cork, September 1998

17 Yule W. Resilience and vulnerability in child survivors of disasters. In: Tizard B, Varma V, eds. Vulnerability and resilience: a festschrift for Ann and Alan B, Varma V, eds. Vulnerability and resilience: a festschrift for Ann and Alan Clarke. London: Jessica Kingsley, 1992:82-98.

18 Dyregrov A. Grief in children: a handbook for adults. London: Jessica Kingsley Publishers, 1991.

19 Yule W, Udwin O. Screening child survivors for post-traumatic stress disorders: experiences from the "Jupiter" sinking. Br $\mathcal{f}$ Clin Psychol 1991;30:131-8

20 Yule W. Post traumatic stress disorder in child survivors of shipping disasters: the sinking of the "Jupiter". Psychother Psychosom 1992;57:200-5.

21 Stallard P, Law F. Screening and psychological debriefing of adolescent survivors of life-threatening events. Br f Psychiatry 1993;163:660-5.

22 Galante R, Foa D. An epidemiological study of psychic trauma and treatment effectiveness after a natural disaster. $\mathcal{F}$ Am Acad Child Psychiatry $1986 ; 25: 357-63$.
23 Farberow NL, Gordon NS. Manual for child health workers in major disasters. Washington, DC: US Government Printing Office, DHHS Publication No. (ADM 81-1070), 1981.

24 Ayalon O. Rescue! Community oriented preventive education for coping with stress. Haifa: Nord Publications, 1988.

25 Yule W, Williams R. Post traumatic stress reactions in children. $\mathcal{F}$ Trauma Stress 1990;3:279-95.

26 Gillis HM. Individual and small-group psychotherapy for children involved in trauma and disaster. In: Saylor CF, ed. Children and disasters. New York: Plenum, 1993:165-86.

27 Pynoos RS, Eth S. Witness to violence: the child interview. 7 Am Acad Child Psychiatry 1986;25:306-19.

28 Rachman S. Emotional processing. Behav Res Ther 1980;18:51-60.

29 Saigh PA. The behavioral treatment of child and adolescent posttraumatic stress disorder. Advances in Behaviour Research and Therapy 1992;14:24775.

30 Shapiro F. Eye movement desensitization and reprocessing: basic principles, protocols and procedures. New York: The Guilford Press, 1995.

31 Smith PA, Yule W. Eye movement desensitization and reprocessing therapy (EMDR) and other rapid treatments. In: Yule W, ed. Post traumatic stress disorder. Chichester: Wiley, 1998:267-84.

32 Yule W. Work with children following disasters. In: Herbert M, ed. Clinical child psychology: social learning, development and behaviour. Chichester: John Wiley, 1991:349-63.

33 Richards D, Lovell K. Imaginal and in-vivo exposure in the treatment of PTSD. In: Yule W, ed. Post traumatic stress disorder Chichester: Wiley, 1998: 239-66.

34 Canterbury R, Yule W. The effects on children of road traffic accidents. In: Mitchell M, ed. The aftermath of road traffic accidents:psychological, social and legal consequences of an everyday trauma. London: Routledge 1997:5969. 